\title{
ChemComm
}

\section{An unsymmetrical pentacene derivative with ambipolar behavior in organic thin-film transistors $\uparrow$}

Cite this: Chem. Commun., 2013, 49, 6725

Received 2nd May 2013, Accepted 23rd May 2013

DOI: $10.1039 / c 3 c c 43270 j$

www.rsc.org/chemcomm

Three new unsymmetrical anthracenyl-pentacene derivatives have been synthesized, characterized using X-ray crystallography, and used as semiconductors in OTFTs. For one derivative, ambipolar charge carrier transport was observed with a hole mobility of $0.2 \mathrm{~cm}^{2} \mathrm{~V}^{-1} \mathrm{~s}^{-1}$ and an electron mobility of $0.03 \mathrm{~cm}^{2} \mathrm{~V}^{-1} \mathrm{~s}^{-1}$.

Organic $\pi$-conjugated systems are promising materials for use in organic thin-film transistors (OTFTs). ${ }^{1}$ Linear acenes, such as pentacene and its derivatives, are prominent examples. ${ }^{2-4}$ Hole mobilities greater than $1 \mathrm{~cm}^{2} \mathrm{~V}^{-1} \mathrm{~s}^{-1}$ have been reported for OTFTs using 6,13-bis(triisopropylsilylethynyl)pentacene as a solution processed semiconductor. ${ }^{4,5}$ The high charge carrier mobility of this derivative has been attributed to effective $2 \mathrm{D}$ $\pi$-stacking in the crystalline state. ${ }^{3,6,7}$ Recent synthetic efforts have also yielded pentacene derivatives with pendent ethynylarene groups designed to increase the active $\pi$-surface of the system. ${ }^{8}$ The ethynyl spacer separates the pentacene core from the arene substituent and allows for a coplanar geometry of the two acenes. In contrast, removing the ethynyl spacer between the two chromophores would give a system in which the $\pi$-system of the pentacene and the appended aryl group are orthogonally arranged due to steric interactions (Scheme 1). It was predicted that the orthogonal orientation of the two chromophores might improve the intermolecular electronic coupling in different

\footnotetext{
${ }^{a}$ Friedrich-Alexander-Universität Erlangen-Nürnberg, Department of Chemistry and Pharmacy \& Interdisciplinary Center of Molecular Materials (ICMM), Henkestraße 42, 91054 Erlangen, Germany. E-mail: rik.tykwinski@chemie.uni-erlangen.de; Fax: +49 913185 26865; Tel: +49 91318522540

${ }^{b}$ Friedrich-Alexander-Universität Erlangen-Nürnberg, Institute of Polymer Materials, Organic Materials and Devices, Martenstraße 7, 91058 Erlangen, Germany.

E-mail: marcus.halik@ww.uni-erlangen.de; Fax: +49 913185 28321; Tel: +4991318527732

${ }^{c}$ Friedrich-Alexander-Universität Erlangen-Nürnberg, Computer Chemie Centrum, Nägelsbachstraße 25, 91052 Erlangen, Germany. E-mail: clark@chemie.unierlangen.de; Fax: +49 913185 26565; Tel: +49 91318522948

$\dagger$ Electronic supplementary information (ESI) available. CCDC 927705-927707. For ESI and crystallographic data in CIF or other electronic format see DOI: $10.1039 / \mathrm{c} 3 \mathrm{cc} 43270 \mathrm{j}$

$\ddagger \mathrm{J}$. T. Margraf is supported by the Beilstein Foundation.
}
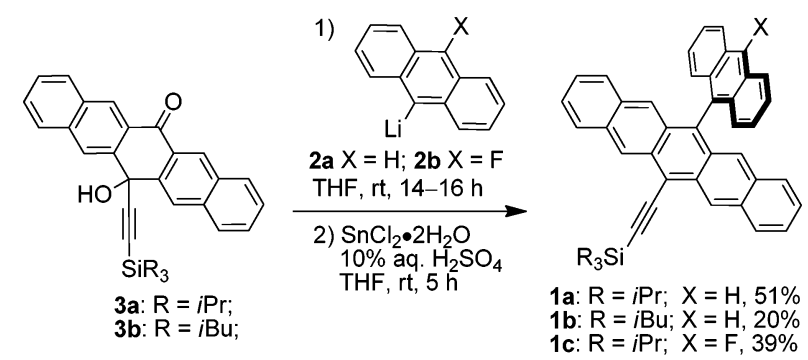

Scheme 1 Synthesis of pentacene derivatives 1a-c.

spacial dimensions, giving useful semiconductors for incorporation into OTFTs. ${ }^{9}$ Guided by this hypothesis, we report the synthesis, characterization, crystal structure analysis, and OTFT devices of a new series of pentacene derivatives 1a-c.

Pentacene derivatives 1a-c were obtained by the reaction of lithiated anthracenes $2 \mathbf{a}, \mathbf{b}^{10}$ with either ketone $\mathbf{3 a}$ or $\mathbf{3} \mathbf{b},{ }^{11}$ followed by reductive elimination with $\mathrm{SnCl}_{2} \cdot 2 \mathrm{H}_{2} \mathrm{O}$. Yields obtained over the two steps were respectable (see ESI $\dagger$ for details).

X-ray crystallographic analysis of 1a-c shows that the anthracene and pentacene groups are nearly orthogonal (torsional angles of $\left.84-90^{\circ}\right)$. The packing of 1a shows $2 \mathrm{D} \pi$-stacking of the pentacenes (Fig. 1a). In addition, the anthracene substituents show $1 \mathrm{D} \pi$-stacking perpendicular to the 2D pentacene bricklayer (see ESI $\dagger$ ). Compound $\mathbf{1 b}$, on the other hand, shows only 1D slipped stacks with interplanar distances of $c a .3 .3$ and $4.1 \AA$ (Fig. 1b) (see ESI $\dagger$ ). Finally, compound 1c shows a 1D pattern with very little $\pi$-overlap, and neighbouring $1 \mathrm{D}$ stacks are oriented $180^{\circ}$ relative to each other (Fig. 1c). This alternate arrangement is likely due to the electronic influence of the fluorine substituent, through increased dipolar interactions and intermolecular edge-to-face interactions (ESI†).

The absorption spectra of 1a-c are nearly identical in the low energy region, showing three peaks at $c a .536,574$, and $622 \mathrm{~nm}$, characteristic of the pentacene chromophore (see ESI $\dagger$ ) and confirming the absence of electronic communication between the anthracene and pentacene groups. ${ }^{12}$ Likewise, the optical band gap $\left(E_{\text {gap }}^{\text {opt }}\right)$ of $\mathbf{1 a - c}$, as estimated from the cutoff of the 

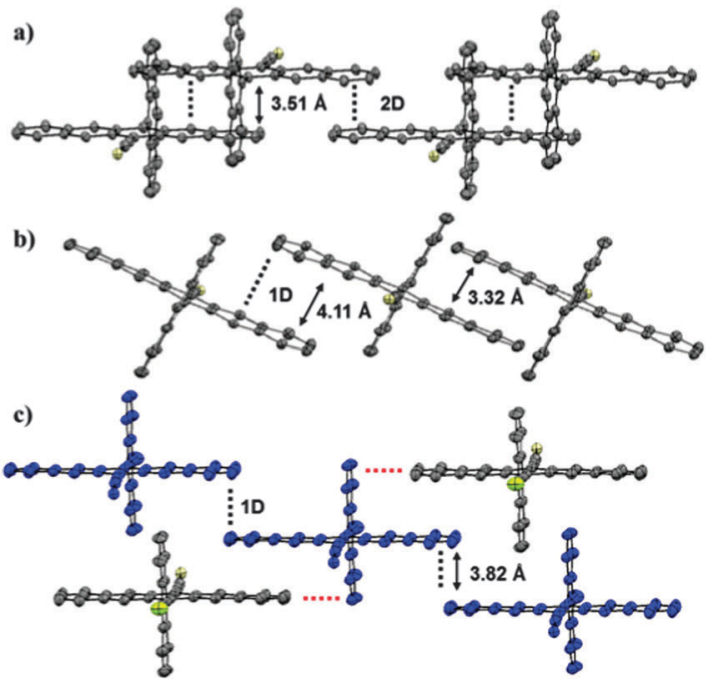

Fig. 1 Crystal structures of 1a-c; (a) 2D brick-wall pattern of 1a; (b) 1D slipped stack packing of $\mathbf{1 b}$; (c) 1D slipped stacks of $1 \mathbf{c}$ (blue), in which edge-to-face/faceto-face interactions between stacks are highlighted by red/black lines (silyl substituents omitted for clarity).

Table 1 Electrical properties of pentacene derivatives $1 \mathrm{a}-\mathrm{c}$

Derivative $\mathrm{HOMO}^{a}(\mathrm{eV}) \mathrm{LUMO}^{a}(\mathrm{eV}) E_{\text {gap }}^{\mathrm{el}}(\mathrm{eV}) E_{\text {gap }}^{\mathrm{opt} b}(\mathrm{eV}) \lambda_{\text {max }}^{\text {off }}{ }^{c}(\mathrm{~nm})$

\begin{tabular}{llllll}
\hline $\mathbf{1 a}$ & -5.17 & -3.21 & 1.96 & 1.92 & 645 \\
1b & -5.16 & -3.19 & 1.97 & 1.93 & 644 \\
1c & -5.17 & -3.16 & 2.01 & 1.93 & 643
\end{tabular}

$\begin{array}{llllll}1 \mathrm{c} & -5.17 & -3.16 & 2.01 & 1.93 & 643\end{array}$

${ }^{a}$ Determined using CV. ${ }^{b}$ Determined using absorption spectroscopy (see ESI). ${ }^{c}$ Determined using the intercept of the tangent applied to the longest wavelength absorption peak and the baseline.

longest wavelength absorption peak $\left(\lambda_{\max }^{\text {off }}\right)$, shows little variance (Table 1, see ESI $\dagger$ for details).

Cyclic voltammetry (CV) has been used to estimate the energy of the highest occupied and the lowest unoccupied molecular orbitals (HOMO and LUMO, respectively, see ESI $\dagger$ ) and the electrical band gap ( $E_{\text {gap }}^{\mathrm{el}}$ ), as summarized in Table 1. There is only a minor influence of structural changes on the redox behavior of 1a-c, suggesting that both the HOMO and the LUMO are fully located on the pentacene chromophore, with little contribution from the anthracene substituent. This premise has also been confirmed by calculations (vide infra).

Thin films of 1a-c were incorporated by thermal evaporation into OTFT devices with a bottom-gate-top-contact architecture using doped $\mathrm{Si}$ wafers with a $100 \mathrm{~nm}$ layer of thermally grown $\mathrm{SiO}_{2}$ as substrates. A thin layer $(20 \mathrm{~nm})$ of $1 \mathbf{a}-\mathbf{c}$ was evaporated directly onto the $\mathrm{SiO}_{2}$ gate dielectric. The Au source and drain electrodes were then defined by thermal evaporation $(30 \mathrm{~nm})$ through a stencil mask. Hole mobilities measured for $\mathbf{1 a - c}$ in the saturation regime were on the order of $\mu_{\mathrm{h}}=10^{-7} \mathrm{~cm}^{2} \mathrm{~V}^{-1} \mathrm{~s}^{-1}$ for devices measured in a glove-box (Table 2, threshold voltages $\left(V_{\text {th }}\right)$, current on/off ratios $\left(I_{\text {on }} / I_{\text {off }}\right)$, and the drain to gate current ratios $\left(I_{\mathrm{D}} / I_{\mathrm{G}}\right)$ are summarized in the ESI $\left.\dagger\right)$. Finally, no n-type behavior was observed for devices on $\mathrm{Si} / \mathrm{SiO}_{2}$ substrates, as expected due to the trapping of electrons by the reactive $\mathrm{SiO}_{2}$ dielectric. $^{13}$
Table 2 Hole $\left(\mu_{\mathrm{h}}\right)$ and electron mobilities $\left(\mu_{\mathrm{el}}\right)$ in the saturation regime of the pentacene derivatives $1 \mathrm{a}-\mathrm{c}$; all values in $\mathrm{cm}^{2} \mathrm{~V}^{-1} \mathrm{~s}^{-1}$

\begin{tabular}{llll}
\hline Derivative $^{a}$ & $\mu_{\mathrm{h}}\left(\mathrm{Si} / \mathrm{SiO}_{2}\right)^{b}$ & $\mu_{\mathrm{h}}\left(\mathrm{AlO}_{x}-\mathrm{C}_{14} \mathrm{PA}\right)^{b}$ & $\mu_{\mathrm{el}}\left(\mathrm{ALO}_{x}-\mathrm{C}_{14} \mathrm{PA}\right)^{b}$ \\
\hline 1a & $1.2 \times 10^{-7 c}$ & - & - \\
1b & $7.1 \times 10^{-7 c}$ & $1.8 \times 10^{-2 d}$ & - \\
1c & $6.8 \times 10^{-7 c}$ & $1.6 \times 10^{-1 d}$ & $7.6 \times 10^{-3 d}$
\end{tabular}

${ }^{a}$ Vapor phase deposition of $1 \mathbf{1 a}-\mathbf{c}$ onto the corresponding substrate.

${ }^{b}$ Devices measured in the glove-box under $\mathrm{N}_{2} \cdot{ }^{c} L=100 \mu \mathrm{m} .{ }^{d} L=$ $60 \mu \mathrm{m} ; W=500 \mu \mathrm{m}$ for all OTFTs.

In order to achieve lower operating voltages for the OTFT devices and to provide a low surface energy interface, which often leads to improved molecular order, ${ }^{14}$ the setup of the OTFT was changed (Fig. 2a). ${ }^{15,16}$ Aluminum gate electrodes were evaporated onto a $\mathrm{Si} / \mathrm{SiO}_{2}$ wafer and patterned by a shadow mask. Subsequent oxidation in $\mathrm{O}_{2}$ plasma yielded an $\mathrm{AlO}_{x}$ layer, approximately $3.6 \mathrm{~nm}$ thick. ${ }^{17}$ The substrate was then immersed in a $0.2-0.3 \mathrm{mM}$ solution of tetradecylphosphonic acid $\left(\mathrm{C}_{14} \mathrm{PA}\right)$ in iso-propanol, which formed a self-assembled monolayer (SAM), yielding an $\mathrm{AlO}_{x}-\mathrm{C}_{14} \mathrm{PA}$ hybrid dielectric with a gate capacitance of $0.72 \mu \mathrm{F} \mathrm{cm} \mathrm{cm}^{-2}$ (see ESI $\dagger$ ). Semiconductors 1a-c were then evaporated onto the $\mathrm{AlO}_{x}-\mathrm{C}_{14} \mathrm{PA}$ hybrid dielectric, followed by the $\mathrm{Au}$ source and drain electrodes. Semiconductor $1 \mathrm{a}$ on the $\mathrm{AlO}_{x}-\mathrm{C}_{14} \mathrm{PA}$ hybrid dielectric did not yield working OTFTs, which has been attributed to an incongruous semiconductor layer on the low surface energy dielectric (see ESI†). On the other hand, $\mathbf{1 b}$ and $\mathbf{1 c}$
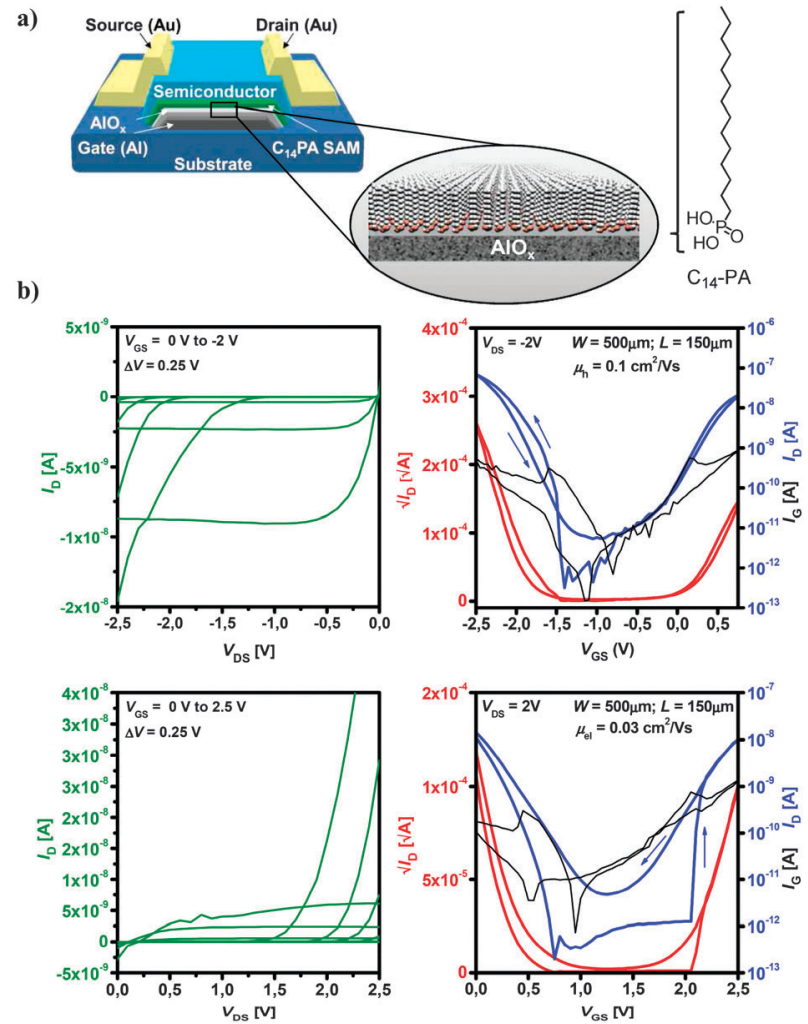

Fig. 2 (a) Schematic representation of the TFT setup using the $A_{1} O_{x}-C_{14} P A$ hybrid dielectric; (b) output (green) and transfer (blue/red) characteristics of $1 \mathrm{c}$ in the saturation regime. 
yielded homogeneous thin-films with connected grains on the SAM surface. These devices exhibited hole mobilities up to $\mu_{\mathrm{h}}=$ 0.05 and $0.2 \mathrm{~cm}^{2} \mathrm{~V}^{-1} \mathrm{~s}^{-1}$, respectively, for $\mathbf{1 b}$ and $\mathbf{1 c}$, with a maximum applied driving voltage of $2.5 \mathrm{~V}$ (Table 2). Thus, mobilities are improved by more than five orders of magnitude compared to devices on the $\mathrm{Si} / \mathrm{SiO}_{2}$ substrate. At the same time, $V_{\text {th }}$ was reduced from approximately $10 \mathrm{~V}$ to $2 \mathrm{~V}$ (see ESI $\dagger$ for details). Additionally, electron transport was obtained for 1c, with mobility $\mu_{\mathrm{el}}=0.03 \mathrm{~cm}^{2} \mathrm{~V}^{-1} \mathrm{~s}^{-1}$.

To characterize the nature of the semiconducting properties of 1a-c, semiempirical AM1 ${ }^{18}$ calculations were performed on nanocrystals, derived from experimental single-crystal X-ray analyses using EMPIRE (each consisting of $>11000$ atoms). ${ }^{19}$ Electron- and hole-transport pathways can be visualized from the local electron affinity $\left(\mathrm{EA}_{\mathrm{L}}\right)$ and ionization potential $\left(\mathrm{IE}_{\mathrm{L}}\right){ }^{20}$ respectively, via a Monte Carlo path search algorithm. The lowest barrier (and therefore most likely) electron pathways involve mainly the $\pi$-systems of the pentacene stacks (Fig. 3a-c) via face-to-face interactions that lead to anisotropic transport behavior. Additional low barrier pathways involving a combination of pentacene and anthracene transitions are found only for 1c (Fig. 3d). On the other hand, hole-transfer pathways favor sites along the edges of the molecules (Fig. 3e-g). The trends found for the energy barriers along these pathways correspond qualitatively to those found for the observed hole mobilities $\left(36.2,55.9\right.$ and $47.8 \mathrm{kcal} \mathrm{mol}^{-1}$ for 1a-c respectively), indicating that hole mobilities are governed by the activated charge transport from molecule to molecule. Electron transfer barriers follow the same trend (55.4, 88.9 and

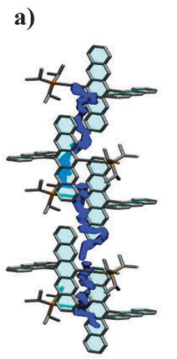

e)
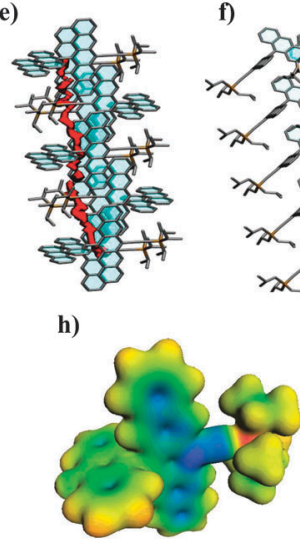

b)

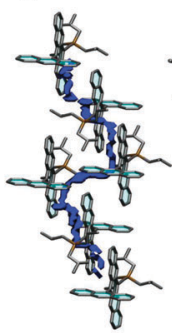

c)

f)

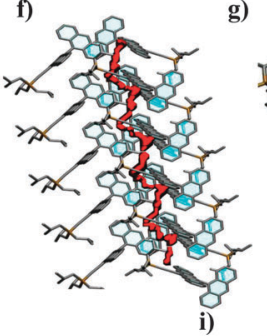

i)

g)

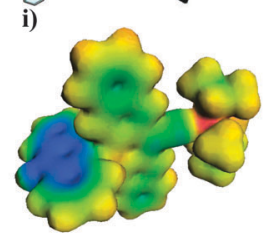

d)
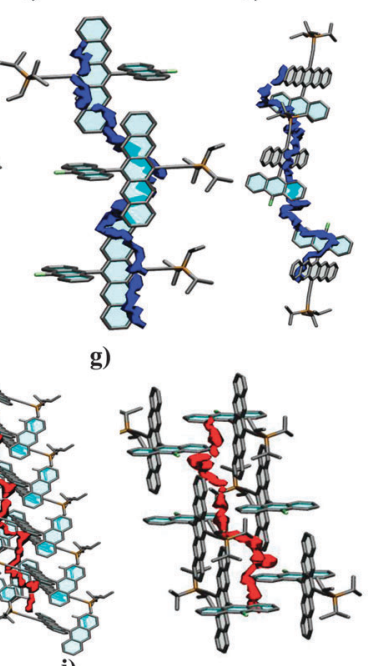

Fig. 3 Electron transfer pathways for (a) 1a, (b) 1b, and (c and d) 1c. Hole transfer pathways for (e) 1a, (f) 1b, and (g) 1c. (h) Molecular electrostatic potential (MEP) mapped on the electron density isosurface of the 1c radical anion, and (i) MEP mapped on the first excited state of the $1 \mathrm{c}$ radical anion (MEP maps: electron density isovalue is $0.017 \mathrm{e}^{-1} \AA^{-3}$, potentials are mapped from -0.45 (blue) to 0.1 (red) $\mathrm{Ha} \mathrm{e}^{-1}$ ).

$86.9 \mathrm{kcal} \mathrm{mol}^{-1}$ ) and are significantly higher, as reflected in the preferred p-type behavior of all devices.

An obvious question is whether fluorination in 1c has an effect beyond changing the crystal structure. ${ }^{21}$ Calculations of the excitation energies of individual molecules in vacuo show that fluorination significantly decreases the first doublet excitation energy of the radical anion $(\mathbf{1 a}=1.648 \mathrm{eV} ; \mathbf{1} \mathbf{b}=1.651 \mathrm{eV}$; $1 \mathrm{c}=1.536 \mathrm{eV}$ ). UNO-CIS molecular electrostatic potential maps (calculated using VAMP $11.0^{22}$ ) of the ground and excited states show that this process involves a shift of negative charge density to the anthracene group (Fig. $3 \mathrm{~h}$ and i). ${ }^{23}$ In other words, fluorination facilitates the participation of the anthracene unit in electron transport.

In summary, we have reported a series of anthracenylpentacene derivatives 1a-c, which show orthogonal arrangement of the two $\pi$-systems. Using a low surface energy $\mathrm{AlO}_{x}-\mathrm{C}_{14} \mathrm{PA}$ hybrid gate dielectric increases hole mobilities by five orders of magnitude for $\mathbf{1 b}$ and $\mathbf{1 c}$ relative to $\mathrm{Si} / \mathrm{SiO}_{2}$ devices. Additionally, electron transport is observed for $\mathbf{1 c}$, which is attributed to the fluorination of the anthracene substituent in 1c.

\section{Notes and references}

1 B. Lucas, T. Trigaud and C. Videlot-Ackermann, Polym. Int., 2012, 61, 374-389.

2 F. Würthner, Angew. Chem., Int. Ed., 2001, 40, 1037-1039.

3 J. E. Anthony, Angew. Chem., Int. Ed., 2008, 47, 452-483.

4 F. Yakuphanoglu and B. Gunduz, Synth. Met., 2012, 162, 1210-1239.

5 S. K. Park, T. N. Jackson, J. E. Anthony and D. A. Mourey, Appl. Phys. Lett., 2007, 91, 63514.

6 J. E. Anthony, J. S. Brooks, D. L. Eaton and S. R. Parkin, J. Am. Chem. Soc., 2001, 123, 9482-9483.

7 D. Lehnherr and R. R. Tykwinski, Materials, 2010, 3, 2772-2800.

8 D. Lehnherr, A. H. Murray, R. McDonald, M. J. Ferguson and R. R. Tykwinski, Chem.-Eur. J., 2009, 15, 12580-12584.

9 X. Zhang, X. Jiang, J. Luo, C. Jing, C. Chunyan, H. Chen and J. Wu, Chem.-Eur. J., 2010, 16, 464-468.

10 L. Zhu, R. O. Al-Kaysi, R. J. Dillon, F. S. Tham and C. J. Bardeen, Cryst. Growth Des., 2011, 11, 4975-4983.

11 D. Lehnherr, A. H. Murray, R. McDonald and R. R. Tykwinski, Angew. Chem., Int. Ed., 2010, 49, 6190-6194; D. Lehnherr, J. Gao, F. A. Hegman and R. R. Tykwinski, Org. Lett., 2008, 10, 4779-4782.

12 A. R. Waterloo, S. Kunakom, F. Hampel and R. R. Tykwinski, Macromol. Chem. Phys., 2012, 213, 1020-1032.

13 L.-L. Chua, J. Zaumseil, J.-F. Chang, E. C.-W. Ou, P. K.-H. Ho, H. Sirringhaus and R. H. Friend, Nature, 2005, 434, 194-199.

14 A. Y. Amin, A. Khassanov, K. Reuter, T. Meyer-Friedrichsen and M. Halik, J. Am. Chem. Soc., 2012, 134, 16548-16550.

15 M. Halik, H. Klauk, U. Zschieschang, G. Schmid, C. Dehm, M. Schütz, S. Maisch, F. Effenberger, M. Brunnbauer and F. Stellacci, Nature, 2004, 431, 963-966.

16 C. Boulas, J. V. Davidovits, F. Rondelez and D. Vuillaume, Phys. Rev. Lett., 1996, 76, 4797-4800.

17 M. Novak, A. Ebel, T. Meyer-Friedrichsen, A. Jedaa, B. F. Vieweg, G. Yang, K. Voitchovsky, F. Stellacci, E. Spiecker, A. Hirsch and M. Halik, Nano Lett., 2011, 11, 156-159.

18 M. J. S. Dewar, E. G. Zoebisch, E. F. Healy and J. J. P. Stewart, J. Am. Chem. Soc., 1985, 107, 3902-3909.

19 T. Clark and M. Hennemann, EMPIRE'12, Erlangen, 2011.

20 B. Ehresmann, B. Martin, A. H. C. Horn and T. Clark, J. Mol. Model, 2003, 9, 342-347.

21 For discussion of crystal engineering related to acene performance, see: (a) C. R. Swartz, S. R. Parkin, J. E. Bullock, J. E. Anthony, A. C. Mayer and G. G. Malliaras, Org. Lett., 2005, 7, 3163-3166; (b) F. Würthner and R. Schmidt, ChemPhysChem, 2006, 7, 793-797.

22 T. Clark, A. Alex, B. Beck, F. Burkhardt, J. Chandrasekhar, P. Gedeck, A. Horn, M. Hutter, B. Martin, P. O. Dral, G. Rauhut, W. Sauer, T. Schindler and T. Steinke, VAMP 11.0, Erlangen, 2011.

23 P. O. Dral and T. Clark, J. Phys. Chem. A, 2011, 115, 11303-11312. 